\title{
Fluorides in Caries Prevention and Control: Empiricism or Science
}

\author{
J.M. ten Cate \\ Department of Cariology/Endodontology/Pedodontology, Academic Centre for Dentistry Amsterdam (ACTA), \\ Amsterdam, The Netherlands
}

\section{Key Words}

Evidence-based dentistry · Fluoride $\cdot$ History of caries research $\cdot$ Remineralization $\cdot$ Review tinue to be directed at improving our understanding of fluoride, in particular on topics where success so far has failed.

Copyright @ 2004 S. Karger AG, Basel

\begin{abstract}
The caries-preventive effects of fluoride are beyond any reasonable doubt! Inclusion of fluoride use in caries prevention protocols has resulted in significant reduction in caries prevalence in the majority of the population. Nevertheless, even in low-caries prevalence populations up to $20 \%$ of individuals may suffer to an unacceptable degree from caries. In the history of caries research various phases can be discerned. Starting with the initial laboratory - studies to reveal the mode of action of fluoride, attention later shifted to intra-oral studies and in situ product testing. Currently much emphasis is given to evidence-based dentistry and guidelines for clinical practice, which trend has also focussed the research on fluoride and caries. While on some topics, such as the efficacy of fluoride toothpastes, evidence is convincing, additional research is indicated to resolve remaining questions. One such question is that of high-prevalence individuals for which a comprehensive research programme focussing both on caries aetiological and behavioural aspects should be further developed. Efforts should con-
\end{abstract}

\section{KARGER}

Fax + 41613061234

E-Mail karger@karger.ch www.karger.com
(C) 2004 S. Karger AG, Basel

0008-6568/04/0383-0254\$21.00/0

Accessible online at: www. karger.com/cre
In recent years, more emphasis is given to evidencebased dentistry, both in the dental curricula and in guidelines for clinical practice. This implies that data generated by the research community are re-evaluated by expert committees, subjected to systematic reviews or become part of large-scale meta-analysis. The outcomes have been consensus reports, clinical guidelines and other official documents. The aim of these activities is to improve dissemination of (reliable) information from research to dental practice, to encourage focussing the research questions and improving the quality of research. In reports prepared by expert groups data are often ranked by the level of evidence. This ranges from strong scientific support for a preventive strategy or product to limited scientific support. A more specific approach is to rank recommendations from evidence from meta-analysis of randomized controlled trials ('hard' data) to evidence obtained from expert opinions (considered 'softer' data). The need for consensus information is currently widely expressed [Newbrun, 2001; Reich, 2001]. Although meta-analyses
Prof. J.M. ten Cate

Department of Cariology/Endodontology/Pedodontology

Academic Centre for Dentistry Amsterdam (ACTA), Louwesweg 1

NL-1066 EA Amsterdam (The Netherlands)

Tel. +31 205188 440, Fax +31 20669 2881, E-Mail JM.ten.cate@acta.nl 
and Cochrane type reviews are needed and provide useful information, they also pose new problems. Scrutinizing previously published studies is not a process free from value judgement [Volpe et al., 1993]. The choice of selection criteria is often subjective, not to mention the political impact of a statement that $90 \%$ of the published work in a field does not stand up to current criteria for good research. In addition, the methodologies of (clinical) research develop and the world in which these studies are performed changes continuously [e.g. Schuller and Kalsbeek, 2003]. As an example: what is the value of a clinical study on a fluoride product performed in a period with a higher caries prevalence, or even when performed today in a population with a different caries prevalence or distribution? Can we extrapolate findings from studies on 12to 15 -year-olds to other age groups? What does a metaanalysis on, for instance, fluoride applications mean in terms of fluoride efficacy for adults, elderly or special groups?

Without question there is convincing evidence for a general efficacy of fluorides in caries prevention. Fluoride as a caries-preventive agent was discovered as the side effect of fluorosis in teeth in areas with elevated levels of fluoride in the drinking water [Beltran-Aguilar et al., 2002]. At the time it was difficult to determine small (sub$\mathrm{ppm}$ ) concentrations of fluoride in drinking water. Nevertheless, the early studies on fluoridation of the drinking water were convincing and initiatives were taken to add various types of fluorides to other oral hygiene products. Generally, fluoridation of the drinking water and of toothpastes is now considered the preferred mode of fluoride administration, appraised by the highest level of evidence [e.g. SBU, 2002]. Likewise, there is overall consensus on the primary mode of action of fluoride. Fluoride can be incorporated into the tissue mineral hydroxyapatite (HAP). Due to the lower solubility of F-HAP, dissolution is reduced in solutions containing its common ions $(\mathrm{Ca}$, phosphate, F), while precipitation is enhanced. These thermodynamically driven reactions are - for dental researchers - translated as 'fluoride inhibits demineralization and enhances remineralization', a sentence found in all modern textbooks of cariology [e.g. ten Cate et al., 2003]. Science more than empiricism has led to the evidence generated on this topic. Other modes of action that are often quoted, like the effects of fluoride on bacteria growth and metabolism, have been demonstrated in carefully designed studies, but their role in and contribution to caries prevention in the real-life 'experiment' are questionable. The literature on the above-mentioned processes is extensive. In the Pubmed database of the Nation- al Library of Medicine, a search of the combination of fluoride and enamel/dentine solubility or de-/remineralization gives over 3,000 'hits'.

Is there equally convincing evidence for the methods of fluoride supplementation? On this topic and that of fluoride formulation, numerous issues have been discussed in the past decades. Sodium fluoride is often quoted as being more effective than other types of fluoride, e.g. monofluorophosphate [Stookey et al., 1993]. Even though this conclusion was challenged [Volpe et al., 1993], most modern toothpastes contain sodium fluoride, unless other fluorides are used for economic reasons (sodium monofluorophosphate with chalk abrasive) or to provide additional antimicrobial benefits (e.g. amine and stannous fluorides). The small differences in efficacy of the fluoride actives are probably outweighed by variables like frequency of use and intra-oral retention of the 'active' component [Chesters et al., 1992; O'Mullane et al., 1997]. Various types of vehicle for fluoride have been proposed. First, there are products used by dental professionals, e.g. high fluoride varnishes, lacquers, rinses, foams. For some of these, Cochrane reviews or meta-analyses have been published [Marinho et al., 2002a, b; van Rijkom et al., 1998]. Such reviews have also been published for fluoride toothpastes [Marinho et al., 2003]. Second, fluoride is added to frequently consumed consumables like salt, sugar or milk [Banoczy et al., 1997; Gyurkovics et al., 1992; Marthaler, 2002]. Many of these initiatives are taken to broaden fluoride use and increase compliance to using fluoride products. Oral hygiene products, notably fluoride toothpastes, rinses, fluoridated toothpicks and floss, have, in total, the largest market, but are only adequately used by dentally motivated individuals. Expert opinion has qualified various treatments (for instance fluoride tablets) as being supported by limited scientific evidence and raised doubts on the additional benefits when they are used in conjunction with fluoridated drinking water or toothpaste [SBU, 2002; SIGN, 2000]. Often, new products are put on the market without a scientific rationale or clinical data.

While in modern prevention we wish to formulate our advice on solid clinical evidence, obtaining such evidence has become increasingly difficult. The turnover time for oral care and restorative products no longer seems to allow for the typical 3-year clinical study, which in turn has been so costly that producers have sought alternative methods of evaluation. These range from more sensitive systems of caries detection with the desired shortened time of clinical experimentation, to advanced laboratory or in situ trials [e.g. Zero, 1995]. However, careful scruti- 
nizing of the latter has increased the number of conditions to be fulfilled (e.g. periodic validation of the model, inclusion of various (gold) standard, number of panellists), such that the advantages have partly evaporated [Zero, 1995].

Studies on fluoride efficacy have gone through various phases in the past decades (fig. 1). After the first discovery of fluoride as a caries-preventive agent, efforts were aimed at unravelling its mode of action. From this period date many publications on in vitro findings and their validation in in situ models. In addition, models were developed to test fluoride-containing products prior to fullscale clinical testing. The next wave of reports deals with drawing conclusions from the previous work in terms of clinical guidelines, evidence-based dentistry, etc. Obviously the ultimate aim of all this work was to improve the oral health of the population.

Although the use of fluoride has caused a substantial decrease in caries prevalence, many patients still suffer from dental caries and current attention has therefore focussed on the group of high-risk individuals. It is not clear whether this group would benefit from new products with increased efficacy, as lack of compliance to proven methods of caries prevention, often as simple as twicedaily tooth brushing, makes this group not likely users of new products. Even products that do not require daily attention to hygiene measures (e.g. slow release fluoride devices) depend on periodic consultation with dental professionals. An intensive prevention programme to highrisk individuals failed as caries incidence in the special attention group and in a corresponding control group was not significantly different [Hausen et al., 2000].

If we confront our knowledge on the aetiology and pathogenesis of dental caries with the current caries prevalence data, several questions emerge. In my view the most prominent one is how much additional success in reducing the overall caries prevalence could be attained by increasing our knowledge of the pathophysiological aspects of caries. Alternatively, should we turn our attention more to behavioural aspects? A detailed analysis of the characteristics of high-risk groups could provide the basis for answering this dilemma. Translating observations on high-risk groups into mode of action studies and designing appropriate models could be a next research aim. In recent years our research group has tried to better understand caries at plaque retention sites with limited access to saliva and fluoride. It was shown that fluoride efficacy at such sites was lower than at freely accessible open enamel or dentin surfaces that are commonly used in laboratory and in situ studies [Lagerweij et al., 1996].

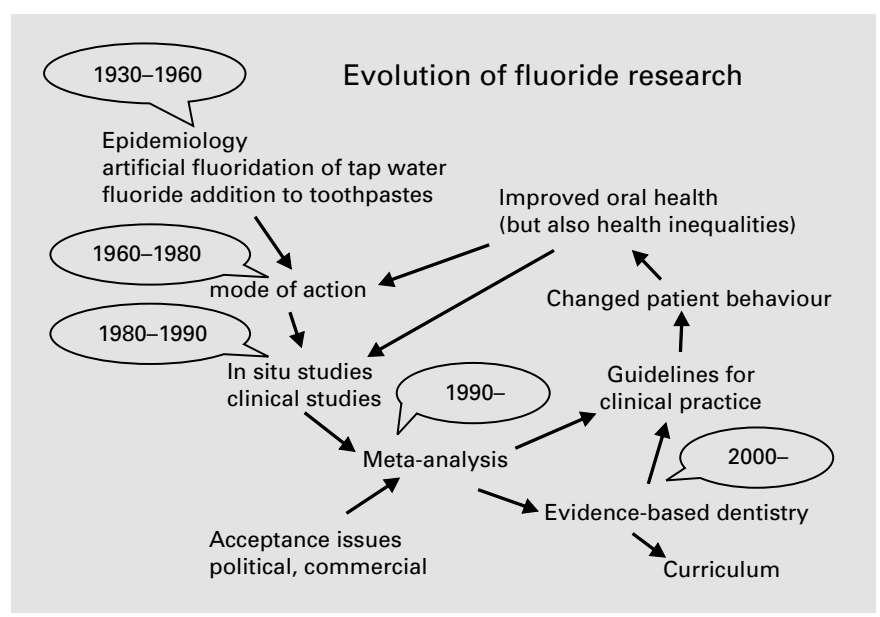

Fig. 1. Developments in fluoride research showing how the focus in research has shifted in time. The current dichotomous nature of caries prevalence in society has resulted in new research questions aimed at understanding specific caries susceptibility issues in the high-prevalence (risk) group.

More specifically on fluoride-related caries-preventive products and protocols many topics should be addressed, such as: The dose-response question of fluoride in toothpastes regarding clinical efficacy is still far from being answered unequivocally. Few and rather old studies have addressed the concentration range $0-1,000 \mathrm{ppm} \mathrm{F}$, which is now under focus for products to be used by small children [Ammari et al., 2003]. Similarly, more studies are indicated in the concentration range above $1,500 \mathrm{ppm}$, where again scarce and conflicting data are available.

In conclusion, caries research has gone a long way and major successes have been made. However, caries is still far from having become extinct and the remaining tasks are difficult but challenging. 


\section{References}

Ammari AB, Bloch-Zupan A, Ashley PF: Systematic review of studies comparing the anti-caries efficacy of children's toothpaste containing 600 ppm of fluoride or less with high fluoride toothpastes of 1,000 ppm or above. Caries Res 2003; 37:85-92.

Banoczy J, Fazekas A, Mari A, Pinter A, Szabo J, Szoke J: Recommendation of the introduction of salt fluoridation for caries prevention in Hungary. Fogorv Sz 1997;90:351-358.

Beltran-Aguilar ED, Griffin SO, Lockwood SA Prevalence and trends in enamel fluorosis in the United States from the 1930s to the 1980s. J Am Dent Assoc 2002; 133:157-165.

ten Cate JM, Larsen MJ, Pearc EIF, Fejerskov O: Chemical interactions between the tooth and oral fluids; in Fejerskov O, Kidd EAM (eds) Dental Caries: The Disease and Its Clinical Management. Munksgaard, Blackwell, 2003. pp 49-69.

Chesters RK, Huntington E, Burchell CK, Stephen $\mathrm{KW}$ : Effect of oral care habits on caries in adolescents. Caries Res 1992;26:299-304.

Gyurkovics C, Zimmermann P, Hadas E, Banoczy $\mathrm{J}$ : Effect of fluoridated milk on caries: 10-year results. J Clin Dent 1992;3:121-124.

Hausen H, Karkkainen S, Seppä L: Application of the high-risk strategy to control dental caries. Community Dent Oral Epidemiol 2000;28:2634.
Lagerweij MD, Damen JJ, ten Cate JM: The effect of a fluoridated toothpaste on dentinal lesions in plaque-filled grooves: An intra-oral crossover study J Dent Res 1996;75:1687-1691.

Marinho VC, Higgins JP, Logan S, Sheiham A: Fluoride varnishes for preventing dental caries in children and adolescents. Cochrane Database Syst Rev 2002a;CD002279.

Marinho VC, Higgins JP, Logan S, Sheiham A: Fluoride gels for preventing dental caries in children and adolescents. Cochrane Database Syst Rev 2002b;CD002280.

Marinho VC, Higgins JP, Sheiham A, Logan S: Fluoride toothpastes for preventing dental caries in children and adolescents. Cochrane Database Syst Rev 2003;CD002278.

Marthaler TM: Dentistry between pathology and cosmetics. Community Dent Oral Epidemiol 2002;30:3-15.

Newbrun E: Topical fluorides in caries prevention and management: A North American perspective. J Dent Educ 2001;65:1078-1083.

O'Mullane DM, Kavanagh D, Ellwood RP, Chesters RK, Schafer F, Huntington E, Jones PR: A three-year clinical trial of a combination of trimetaphosphate and sodium fluoride in silica toothpastes. J Dent Res 1997;76:1776-1781.

Reich E. How to measure the effects of fluoride treatments in clinical trials? The role of caries prevalence and caries assessment. Caries Res 2001;35(suppl 1):34-39. van Rijkom HM, Truin GJ, van't Hof MA: A metaanalysis of clinical studies on the caries-inhibiting effect of fluoride gel treatment. Caries Res 1998;32:83-92.

SBU: Prevention of Dental Caries: A Systematic Review. Rep No 161. Swedish Council on Technology Assessment in Health Care, 2002, pp 1-26.

Schuller AA, Kalsbeek H: Effect of the routine professional application of topical fluoride on caries and treatment experience in adolescents of low socio-economic status in the Netherlands. Caries Res 2003;37:172-177.

SIGN, Scottish Intercollegiate Guidelines Network: Preventing dental caries in children at high caries risk. SIGN Publication 47, 2000.

Stookey GK, DePaola PF, Featherstone JD, Fejerskov O, Moller IJ, Rotberg S, Stephen KW, Wefel JS: A critical review of the relative anticaries efficacy of sodium fluoride and sodium monofluorophosphate dentifrices. Caries Res 1993;27:337-360

Volpe AR, Petrone ME, Davies RM: A critical review of the 10 pivotal caries clinical studies used in a recent meta-analysis comparing the anticaries efficacy of sodium fluoride and sodium monofluorophosphate dentifrices. Am J Dent 1993;6:S13-S42.

Zero DT: In situ caries models. Adv Dent Res 1995;9:214-230. 